\title{
Determination of Effective Dosage of Phyllanthus niruri to Modulate Stress in Tilapia, Oreochromis niloticus
}

\author{
Md Ibrahim, Mursalin Khan, Jesse Rinard, Ahmed Mustafa ${ }^{*}$ \\ Department of Biology, Indiana University-Purdue University Fort Wayne, USA
}

Copyright (C) 2015 by authors, all rights reserved. Authors agree that this article remains permanently open access under the terms of the Creative Commons Attribution License 4.0 International License

\begin{abstract}
A study was performed to determine the effects of supplementing Phyllanthus niruri, an herbal medicinal plant found worldwide and its optimal dosage to modulate stress in tilapia. Phyllanthus niruri-extract from three different sources (suppliers) was given to study fish through supplementation to commercial fish feed at the rate of $1 \%, 2 \%, 5 \%$, and $10 \%$ concentration. Administration of $5 \%$ Phyllanthus niruri from Source B significantly reduced blood glucose in fish.
\end{abstract}

Keywords Tilapia, Stress, Nutraceutical, Phyllunthus, Glucose

\section{Introduction}

The world's population is rising and the subsequent demand for high protein sources of food is rising with it $[1,2$, 3]. Aquaculture offers a solution to these issues by providing a high protein food that requires less space to farm, a faster harvest time, lower cost to produce, imparting minimum threat to the environment.

With the increase in intensification of aquaculture chances of fish getting diseases are also on the rise. Antibiotics, therefore, are excessively in use to cope with the disease prevalence and subsequent mortality. When stressed, fish become susceptible to diseases that can spread rapidly in close quarters $[4,5]$. In order to provide solutions to these problems of farming and the needs of the people without the use of potentially harmful substances many researchers are looking into the use of nutraceuticals in feed in order to decrease stress responses, increase immune responses, increase growth, and increase the nutritional value of farmed fish.

Many researchers have been using herbal plants as nutraceuticals (feed additives) to modulate stress and boost the immune system $[6,7]$. Natural plant products have been reported to have various properties, such as stress reduction, growth promotion, appetite stimulation, and immunostimulation in fish and shellfish due to their active components, such as alkaloids, flavanoids, pigments, phenolics, terpenoids, steroids and essential oils [6, 7].

Phyllanthus niruri, also known as stone breaker, is an herbal medicinal plant under Euphorbiaceae family, available in tropical areas and Amazon. Human being has been using it to relieve pain and inflammation, cure viral and bactericidal diseases, and reduce glucose levels in blood [8]. From research, better growth and survival rate were also reported when Indian carp Rohu, Labeo rohita, [9] and Goldfish, Carassius auratus [10] were fed Phyllathus niruri supplemented feed. Goldfish, Carassius auratus [10] also showed their resistance to A.hydrophila infections when given feed supplemented with Phyllathus niruri [10]. But there was no research done on reducing stress using the same supplement.

Hyperglycemia, increased level of glucose, is a common indicator of acute stress for fish. So, any ingredients which can induce the reduction of glucose level in fish can be considered as stress reliever [11]. As it has been established that Phyllanthus niruri can reduce the blood glucose level in higher vertebrates [7], we want to investigate if it can also reduce the stress in lower vertebrates, such as fish, and thereby increase the immune response. Since, our study will be the first of a kind, we decided to run a pilot study to determine the right dosage of Phyllanthus niruri to produce the best response. We have chosen tilapia as the fish model since tilapia, Oreochromis niloticus, is widely used in aquaculture industries throughout the world.

\section{Materials and Methods}

\subsection{Experimental Design}

Disease free juvenile tilapia (Oreochromis niloticus) with average weight of $38 \pm 2 \mathrm{~g}$ and average length of $13 \pm 2 \mathrm{~cm}$ were obtained from a certified fish hatchery and kept under optimal conditions in a recirculating system for acclimation. Once, acclimated (over a 4 weeks period), fish were randomly assigned to four treatment groups, each group with two replicates: Control feed, Supplemented feed from 
Source A, Supplemented feed from Source B, and Supplemented feed from Source C. Each treatment group was further divided into two rearing environments: Controlled environment (fish kept in optimal density; $5 \mathrm{~g} / \mathrm{l}$ ) and Stressed environment (fish kept in crowded density; 30 $\mathrm{g} / \mathrm{l})$. All fish were given controlled feed for first week and then controlled feed with supplemented nutraceutical (Phyllunthus niruri) for the second week at the concentration of $1 \%, 2 \%, 5 \%$, and $10 \%$ to determine the best source and the best concentration (dosage).

Commercial feed (Aquamax Fingerling Starter 300) was purchased from PMI Nutrition International (MO, USA) and Phyllanthus extracts were purchased from three different suppliers. Extracts were mixed with the commercial feed at $1 \%, 2 \%, 5 \%$, and $10 \%$ of total ingredients by weight thoroughly and homogenously. The feed was then allowed to dry for 24 hours before being stored in airtight containers. All groups of fish were fed once daily to satiation and the amount of food recorded by weight in grams. The trial was run for 2 weeks. Fish were sampled at day 0 , day 7, and day 14 to measure the levels of stress namely, blood levels of glucose as glucose is known as the valid indicator stress in fish [16].

\subsection{Fish Maintenance}

Water quality (dissolved oxygen, $\mathrm{pH}$, ammonia) was monitored and maintained at the optimal level regularly throughout the experimental period. All experiments were conducted following good laboratory practices and fish were cared for according to the guidelines of the Purdue Animal Care and Use Committee.

\subsection{Sampling}

A sample of six fish from each group was taken and euthanized using Tricane Methane Sulphonate (MS222) @ $200 \mathrm{mg} / \mathrm{l}$ within 2 minutes of catching to reduce handling stress. Blood glucose concentration was determined using a glucometer (Freestyle, Abbott Laboratories; Abbott Park, IL) as validated by Wedemeyer et al. [12].

\subsection{Data Analyses}

The data obtained was analyzed using SigmaPlot ${ }^{\circledR}$ 12.5, 2013. The means and standard errors of the means were calculated for each assay by one way analysis of variance (ANOVA), and differences where considered significant when $\mathrm{P}<0.05$. Tukey's comparison of multiple means test was performed post-ANOVA to determine any differences between groups. The graphs included present means \pm standard errors of the means.

\section{Results and Discussion}

Surges in blood glucose concentrations within stressed fish are hallmark indicators of the stress response within fish $[12,13,14]$. Elevated plasma glucose levels have been associated with reduced coronary blood flow [15] and impaired immune response [16]. In our study, supplementation of Phyllanthus niruri to commercial fish feed attenuated blood glucose concentrations to levels similar to the glucose concentrations seen in day 0 samples is concurrent with prior research on glucose homeostasis [17].

While blood glucose concentrations showed significant decline by different concentrations of different sources, indicating Phyllanthus niruri's antihyperglycemic properties, $5 \%$ concentration worked best over the study period. We believe the supplemented Phyllanthus niruri enhances plasma glucose reuptake within the cells of the fish; regardless of stress. A reduction in blood plasma can lead to greater energy expenditure by fish to pump blood to their tissues, therefore leading to elevated plasma glucose levels and in extreme cases, exhaustion [13, 14]. Furthermore, stress induced hyperglycemia can lead to insulin-resistance which can reduce blood flow within skeletal tissues [18]. Studies on other animal models, along with its antihyperglycemic properties, Phyllanthus niruri has been shown to induce vascular relaxation in arteries while enhancing greater blood flow through induction of the synthesis of endothelial nitrous oxide synthase within arteries, and offered protection against hypercholesterolemia within mice [19].

Based on these finding, we are now conducting a detailed study on the effects of Phyllanthus niruri on the modulation of stress and immune response in tilapia raised in aquaculture conditions. 
Table 1. Effects of different concentrations of Phyllanthus niruri extracts obtained from three different suppliers on blood glucose of tilapia reared in two different environments (controlled with optimal density and stressed with high density). Colum 7 indicates $\%$ changes in blood glucose concentrations ( $+/-)$ (compared between Day 7 and Day 14) incorporated into 'heat-maps' (smaller bar indicates bigger reduction) and Colum 8 indicates P values of the same.

\begin{tabular}{|c|c|c|c|c|c|c|c|}
\hline \multirow{2}{*}{$\begin{array}{l}\text { Supplement } \\
\text { Type }\end{array}$} & \multirow{2}{*}{$\begin{array}{l}\text { Supplement } \\
\text { Conc.(\%) }\end{array}$} & \multirow{2}{*}{$\begin{array}{l}\text { Fish Culture } \\
\text { Environment }\end{array}$} & \multicolumn{3}{|c|}{ Conc. Of Blood Glucose (mg/dl) } & \multirow{2}{*}{$\begin{array}{l}\% \text { change in Blood Glucose } \\
\text { (Day7 to 14) }\end{array}$} & \multirow[t]{2}{*}{ P-value } \\
\hline & & & Day 0 & Day 7 & Day 14 & & \\
\hline Control & 0 & Control & 29 & 33.33 & 34.78 & \begin{tabular}{|r|} 
\\
\end{tabular} & 0.009 \\
\hline Control & 0 & Stressed & 29 & 34.05 & 40.66 & 19.41 & 0.024 \\
\hline Source A & 1 & Control & 29 & 34.33 & 35 & 1.95 & 0.561 \\
\hline Source A & 1 & Stressed & 29 & 25.33 & 32.67 & 28.98 & 0.137 \\
\hline Source A & 2 & Control & 29 & 30 & 28 & -6.67 & 0.07 \\
\hline Source A & 2 & Stressed & 29 & 40.67 & 29.33 & -27.88 & 0.09 \\
\hline Source A & 5 & Control & 29 & 34 & 26 & -23.53 & 0.0006 \\
\hline Source A & 5 & Stressed & 29 & 44.67 & 28.33 & -36.58 & 0.0009 \\
\hline Source A & 10 & Control & 29 & 36 & 27 & -25.00 & 0.0003 \\
\hline Source A & 10 & Stressed & 29 & 63.33 & 37.33 & -41.05 & 0.169 \\
\hline Source B & 1 & Control & 29 & 33.33 & 26 & -21.99 & 0.002 \\
\hline Source B & 1 & Stressed & 29 & 43.33 & 50.33 & 16.16 & 0.62 \\
\hline Source B & 2 & Control & 29 & 29.67 & 32.33 & 8.97 & 0.099 \\
\hline Source B & 2 & Stressed & 29 & 26.33 & 28 & 6.34 & 0.796 \\
\hline Source B & 5 & Control & 29 & 37 & 21.67 & -41.43 & 0.00002 \\
\hline Source B & 5 & Stressed & 29 & 40 & 42.33 & 5.83 & 0.857 \\
\hline Source B & 10 & Control & 29 & 24 & 29.66 & 23.58 & 0.0058 \\
\hline Source B & 10 & Stressed & 29 & 47.33 & 70.33 & 48.59 & 0.6 \\
\hline Source C & 1 & Control & 29 & 31 & 27 & -12.90 & 0.008 \\
\hline Source C & 1 & Stressed & 29 & 78.33 & 51 & -34.89 & 0.487 \\
\hline Source C & 2 & Control & 29 & 25 & 25.33 & 1.32 & 0.768 \\
\hline Source C & 2 & Stressed & 29 & 44 & 38.33 & -12.89 & 0.497 \\
\hline Source C & 5 & Control & 29 & 26 & 28 & 7.69 & 0.077 \\
\hline Source C & 5 & Stressed & 29 & 49.33 & 31 & -37.16 & 0.341 \\
\hline Source C & 10 & Control & 29 & 30.67 & 28 & -8.71 & 0.467 \\
\hline Source C & 10 & Stressed & 29 & 53.33 & 60.67 & 13.76 & 0.399 \\
\hline
\end{tabular}

\section{REFERENCES}

[1] A. C. Aguiar, S. M. Cottica, M. Boroski, C. C. Oliveira, E. G. Bonafe, P. B. Franca, and J. V. Visentainer. Quantification of Essential Fatty Acids in the Heads of Nile Tilapia (Oreochromis niloticus) Fed with Linseed Oil. Journal of the Brazilian Chemical Society,22: 643-647, 2011.

[2] S. Diver. Aquaponics - Integration of Hydroponics with Aquaculture. National Sustainable Agriculture Information Service, 1-27, 2006.

[3] J. E. Rakocy, M. P. Masser, and T. M. Losordo. Recirculating aquaculture tank production systems: aquaponics-integrating fish and plant culture. SRAC Publication,454: 1-16, 2006.

[4] K. D. Black and A. D. Pickering. Biology of farmed fish: Sheffield Academic Press, 1998.

[5] J. E. Halver and R. W. Hardy. Fish nutrition: Academic Press, 2002.

[6] T. Citarasu. Herbal biomedicines: a new opportunity for aquaculture industry. Aquaculture International, 18: 403-414, 2010.

[7] V. Sivaram, M. M. Babu, T. Citarasu, G. Immanuel, S. Murugadass, and M. P. Marian. Growth and immune response of juvenile greasy groupers (Epinephelus tauvina) fed with herbal antibacterial active principle supplemented diets against Vibrio harveyi infections. Aquaculture, 237: 9-
$20,2004$.

[8] L. Taylor. Tropical Plant database; raintree. Retrieved $(1 / 20 / 2015)$ from

http://www.rain-tree.com/chanca.htm\#.VIT48HtQAtM, 2013.

[9] P. Govind, S. Madhuri, and Y. P. Sahni. Beneficial effects of certain herbal supplements on the health and disease resistance of fish. Novel Science International Journal of Pharmaceutical Sciences, 1: 497-500, 2012

[10] B. Ahilan. Nithiyapriyatharshini, A., Ravaneshwaran, K. Influence of certain herbal additives on the growth, survival and disease resistance of goldfish, Carassiusauratus (Linnaeus). Journal of Veternary Animal Science, 6: 5-11, 2010.

[11] M. R. Hossain, E. J. Blumenthal, and A. Mustafa. Effects of puerarin on the reduction of glucose and promotion overall health in acutely stressed Chinook salmon (Oncorhynchus tshawytscha). ACTA Ichthyologica et Piscatoria, 43: 85-93, 2013.

[12] G. Wedemeyer, B. Barton, and D. McLeay. Stress and acclimation. Methods for fish biology. American Fisheries Society, Bethesda, Maryland, 451-489, 1990.

[13] B. Barton and G. Iwama. Physiological changes in fish from stress in aquaculture with emphasis on the response and effects of corticosteroids. Annual Review of Fish Diseases, 3-26, 1991.

[14] S. Bonga. The stress response in fish. Physiological Reviews, 77: 591-625, 1996. 
[15] Yokoyama, I., T. Ohtake, S. Momomura, S. Woo-Soo, J. Nishikawa, J. Sasaki, and M. Omata. Hyperglycemia rather than insulin resistance is related to reduced coronary flow reserve in NIDDM. Diabetes, 47: 119-124, 1998.

[16] Mustafa, A., C. MacWilliams, N. Fernandez, K. Matchett, G. Conboy, and J. Burka. Effects of sea lice, Lepeophtheirus salmonis infestation on non-specific defense mechanisms in Atlantic salmon, Salmo salar. Fish and Shellfish Immunology, 10: 47-49, 2000.

[17] Hsu, F., I. Liu, D. Kuo, W. Chen, H. Su, and J. Cheng. Antihyperglycemic effect of puerarin in streptozotocin-induced diabetic rats. Journal of Natural
Products, 66:788-792, 2003.

[18] Laakso, M., S. Edelman, G. Brechtel, and A. Baron. Decreased effect of insulin to stimulate skeletal muscle blood flow in obese man. A novel mechanism for insulin resistance. Journal of Clinical Investigation, 85: 1844-1852, 1990.

[19] Yeung, D., S. Leung, Y. Xu, P. Vanhoutte, and R. Man. Puerarin, an isoflavnoid derived from Radix puerariae, potentiates endothelium-independent relaxation via the cyclic AMP pathway in porcine coronary artery. European Journal of Pharmacology, 552: 105-111, 2006 